\title{
Ciências sociais no Cone Sul e a gênese de uma elite intelectual (1940-1965)
}

\author{
Alejandro Blanco \\ Tradução de Luiz Carlos Jackson
}

Em meados dos anos de 1960, Gino Germani reconhecia com satisfação que na América Latina

[...] havia aparecido um novo tipo de sociólogo, o "cientista social" [...] dedicado exclusivamente ao desenvolvimento de sua disciplina [e que] havia começado a substituir nas universidades mais importantes do continente 0 antigo professor, advogado, político, administrador, para quem a cátedra universitária era 0 apêndice honorífico de sua profissão principal [...] (Germani, 1964, p. 1).

N esse momento, as ciências sociais haviam se autonomizado no sistema de educação superior, a partir do estabelecimento de carreiras e cursos de sociologia (de graduação e pós-graduação), e, com isso, uma nova classe de produtores intelectuais, a dos cientistas sociais, detentores de competência intelectual e técnica exclusiva, depositários de formação acadêmica inovadora e auto-representados como uma elite intelectual moderna, ingressava na vida pública e intelectual das sociedades da América Latina.

Q uais foram as condições gerais e específicas que possibilitaram a emergência dessa nova categoria de produtores culturais? Em que contexto ocorreu essa renovação intelectual e quais foram os dispositivos institucionais que lastrearam essa nova atividade intelectual? Q uem constituiu essa nova elite intelectual? Em torno de quais lideranças se formou a nova ciência 
social? Q uem patrocinou a implantação desses novos empreendimentos intelectuais?

Em princípio, a emergência dessa nova elite intelectual resultou da conjunção deuma sériedeiniciativas domésticas dessesnovos produtores culturaisa favor deuma renovação radical dasciências sociaiseda pressão exercida por uma série deorganismosinternacionaiseregionais, em defesa da modernização da educação superior em geral eda ciência social em particular. Com efeito, ecomo soeocorrer com todainovação intelectual einstitucional relevante, o reconhecimento público de que gozou por um tempo a "sociologia científica" na América Latina - tanto que seria invocada aqui e ali como 0 modelo da sociologia tout court - deveu-se à conjunção singular de quadros derecepção maisou menosfavoráveise ao esforço, militantee denodado, de autopromoção por parte deseus principaisimpulsores. M as o fenômeno foi menos o resultado de uma ação concertada ou planejada do que o fruto de uma série de iniciativas locais, regionais e internacionais, de diferentes ope rações culturais, assim como de projetos de diferentes atores com interesses políticos, cognitivoseinstitucionais diversos, quegradualmente, eem virtude de uma série de condições políticas e institucionais, resultaram convergentes eal cançaram um importantegrau de articulação.

Este trabalho explora, então, o processo constitutivo e a ascensão desse segmento das elites intelectuais, por meio de uma reconstrução das distintas iniciativas e dos principais dispositivos culturais e institucionais de difusão eimplantação. Ainda queo título desteartigo remeta às ciências sociais, a investigação terá como foco, a rigor, a sociologia. Entre outras razões porque no período estudado foi essa disciplina que liderou o movimento de renovação intelectual. U ma segunda delimitação concerne à área geográfica. Como seu título indica, o trabalho focaliza a experiência que teve lugar no Cone Sul e deixa um pouco de lado outras igualmente importantes sobretudo a mexicana e a brasileira.

Institucionalização

É bem conhecida a implantação precoce do ensino de sociologia nas universidades de al guns países da América Latina. Em 1877, foi criado na cidade de C aracas, Venezuela, um Instituto de Ciências Sociaise, anos mais tarde, em 1882, a U niversidade de Bogotá abriu o primeiro curso de sociologia no mundo, antecipando-se assim em dez anos ao inaugurado em Chicago em 1892. D aí em diante, esse processo se expandiu: 1898 em Buenos 
Aires; 1900 em Assunção; 1906 em Caracas, La Plata e Q uito; 1907 em Córdoba, Guadalajara e Cidade do M éxico. Até os anos de 1920, o ensino de sociologia já estava estabelecido em quase todos os países da América Latina, em várias universidades (cf. Poviña, 1941).

Contudo, é em torno dos anos de 1940 que a sociologia experimenta, ainda que com ritmos e intensidades desiguais, um processo mais firme de institucionalização. A parecem os primeiros centros de ensino, as primeiras instituições especializadas em estudos sociológicos, as primeiras publicações oficiais, as primeiras coleções de livros e, também, algumas organizações formais da disciplina. Ainda que no Brasil a implantação do ensino de sociologia tenha sido um fenômeno relativamente tardio, de 1930 em diante, a disciplina cresceu mais rápido do que em outros países da região. Em 1933, foi criada em São Paulo a primeira escola de sociologia, a Escola Livre de Sociologia e Política, antecipando-se em mais de vinte anos às que apareceram em outros países, e, em 1934, a Faculdade de Filosofia, Ciências e Letras da U niversidade de São Paulo. N o M éxico, Lucio M endieta y $\mathrm{N}$ úñez pôs em funcionamento o Instituto de Pesquisas Sociais na U niversidade N acional Autônoma do M éxico (1939) e, no ano seguinte, na Argentina, foram criados o Instituto de Sociologia, na Faculdade de Filosofia e Letras da Universidade de Buenos Aires, e o de Investigações Econômicas e Sociológicas, na U niversidade N acional de Tucumán, dirigidos por Ricardo Levene e Renato Treves, respectivamente.

Também nesses anos foram editadas as primeiras publicações especializadas: Sociologia, em São Paulo (1939), Revista M exicana deSociología (1939), Revista Interamericana deSociología de C aracas (1939) e Boletín del Instituto de Soci ología, da U niversidade de Buenos Aires (1942), entre outras. Também as primeiras coleções de livros: "Sección de 0 bras de Sociología", editada pela Fondo de Cultura Económica, sob a direção de Josém edina Echavarría, "Biblioteca de Sociología”, da editora Losada, dirigida por Francisco Ayala, "Cienciay Sociedad" e "Biblioteca de Psicología Social y Sociología", ambas sob a direção de G ino G ermani, nas editoras A bril e Paidós, respectivamente. Constituem-se no período, ainda, algumas das organizações formais da disciplina, como a Academia Argentina de Sociologia, a Sociedade Brasileira de Sociologia e a Sociedade M exicana de Sociologia. A criação, em 1950, da Associação Latino-Americana de Sociologia, a primeira associação regional do mundo, selou esse primeiro capítulo de institucionalização da sociologia, uma vez que garantiu ao processo um forte acento regional - que logo seria amplificado pela nova geração (cf. Blanco, 2006). 
0 estabelecimento do ensino é, portanto, anterior ao da "sociologia científica". Vejamos como isso ocorreu. Em princípio, ena falta de um estatuto independente, o ensino da disciplina, com exceção daE scola deSociologiae Política deSão Paulo, não pretendia formar sociólogos, mas oferecer a estudantes de outras carrei ras uma espécie de complemento cultural relativo ao conhecimento dos fenômenos sociais. N esse sentido, a inserção da sociologia no contexto universitário não era a de uma disciplina autônoma, mas "auxiliar" das - ou subordinada às - disciplinas já estabelecidas, fundamentalmente o direito e a filosofia. U ma rápida análise morfológica revela que a maioria dos professores de sociologia era formada em direito. Além disso, 0 ensino era, freqüentemente, apenasuma atividade secundária. Algumastrajetórias indicam, também, que a carreira intelectual não se dissociava da carreira política. O s sociólogos podiam ser profissionais da sociedade ou professoresuniversitários, masnão se esperava que realizassem investigações empíricas. A maioria deles desconfiava da sociologia empírica, identificada com a sociologia norte-americana, tida como "aplicada", "naturalista" ou "como mero catálogo de fenômenos sociais", mas sempre negativamente. Também a produção intelectual dessa geração de sociólogos revelava seu perfil intelectual: o ensaio político, a história dasidéias, o manual e o tratado tornaram-se os gêneros mais difundidos.

Foi nesse contexto que se manifestaram os primeiros sinais de insatisfação intelectual, a favor de uma renovação radical no âmbito da sociologia. Formou-se um movimento intelectual que pretendia constituí-la como ciência empírica. $\mathrm{N}$ os meios de língua espanhola, o livro pioneiro nessa direção foi Sociología: teoría y método, de José M edina Echavarría, publicado em 1941, obra que G ermani saudaria décadas mais tarde como a que teria iniciado "a onda da sociologia científica na América Latina". No prólogo à primeira edição, M edina Echavarría escrevia:

Uma ciência sociológica não pode existir sem teoria e sem técnica de pesquisa. Sem uma teoria, isto é, sem um quadro de categorias depurado e um esquema unificador, o que se chama sociologia não apenas não será uma ciência como carecerá de significação para a investigação concreta e a resolução dos problemas sociais do dia. Sem uma técnica de pesquisa definida, submetida a cânones rigorosos, a investigação social não apenas é infecunda, mas convida à ação sempre disposta do charlatão e do audaz. [...] A sociologia tem sido sempre castigada pela improvisação, e esta deve ser cortada pela raiz (1941, p. 8). 
Como exemplo bem-sucedido dessa nova situação, M edina Echavarría mencionava o caso da "sociologia norte-americana" no capítulo "A investigação social e suas técnicas". Essa referência remota à experiência norteamericana é muito significativa em um contexto em quea sociologia alemã constituía o universo de referência quase exclusivo entre os praticantes da disciplina (cf. Blanco, 2004). Poucos anos depois, a referência à sociologia norte-americana tornar-se-ia um dispositivo central de legitimação na renovação da disciplina.

$\mathrm{N}$ a Argentina, os primeiros sinais dessa mudança foram sentidos no Instituto de Sociologia de Buenos Aires, por meio da figura de Gino Germani. Aqui também a renovação da disciplina associou-se a esse duplo movimento presente em M edina Echavarría: fazer da sociologia uma ciência empírica e aplicada, toman do como referência principal a sociologia norte-americana. Em um ensaio desses anos, ao tratar das relações entre sociologia e planificação, G ermani sustentava que "a sociologia não pode deixar de ser uma ciência empírica e indutiva se verdadeiramente pretende cumprir sua função orientadora em uma sociedade que se encaminha para a planificação" (G ermani, 1946a). Essa declaração adotou a forma de um argumento mais sistemático em um ensaio inédito redigido em 1946, Teoría e investigación en la sociología empírica (cf. G ermani, 1946b), voltado precisamente ao exame da "possi bilidade de uma ciência empírica da realidade social", e cujos argumentos seriam reunidos dez anos mais tarde em La sociología científica: apuntes para su fundamentación, uma espécie de manifesto do movimento de renovação. Com efeito, 0 texto reunia os pontos que aqui $\mathrm{e}$ ali haviam sido assinalados como parte dessa reforma radical dos ideais intelectuais da disciplina, fundamentalmente o de incorporar a investigação social esuas técnicas às tarefas da sociologia, sublinhando ao mesmo tempo a relevância da teoria na investigação social.

I solados inicialmente, todos esses sinais de renovação adquiriram, atéa segunda metade dos anos de 1950, a forma deum movimento maisamplo e sistemático. José M edina Echavarría, Florestan Fernandes e Gino Germani foram, talvez, suas figuras mais expressivas, mas não as únicas. Luiz de Aguiar Costa Pinto falaria do "variado contingente de aventureiros" para destacar o campo da pesquisa social e, do C hile, Eduardo $\mathrm{H}$ amuy lamentava-se pelo fato de que "o ambiente de nosso país considera o sociólogo um ser acadêmico ou um aficcionado entusiasta no lugar de um investigador sério e científico dos problemas sociais" (Brunner, 1985). Expressões semeIhantes seriam pronunciadas por ocasião do V Congresso Latino-America- 
no deSociologia, ocorrido em M ontevidéu no ano de1959, por C. A. C ampos Jiménez, da Costa Rica, J. R. Arboleda, da Colômbia, e J. A. Silva M ichelena, da Venezuela. Finalmente, do M éxico, Pablo González Casanova iniciava um protesto parecido na Escola $\mathrm{N}$ acional de Ciências Políticas e Sociais. Por meio dessas figuras, eno transcurso de poucosanos, teria início a montagem de uma aliança fundada na reconhecida necessidade de uma reorganização intelectual einstitucional da disciplina.

D e todo modo, iniciou-se uma disputa entre os que reclamavam a identidade de sociólogos. 0 conflito dividiu o campo em duas facções: a dos "sociólogos de cátedra" ea dos "sociólogos científicos". Ambos lutavam pelo controle desse campo intelectual, almejavam para si a identidade de sociólogos e aspiravam representar nacional e internacionalmente a disciplina. Aos ol hos dos renovadores, os já estabelecidos tinham uma formação paroquial e antiquada, limitada ao conhecimento enciclopédico das principais tradições e escolas de sociologia. O s novos, diferentemente, declaravam-se portadores dos rudimentos da "nova ciência" (que al guns haviam assi milado nos Estados Unidos e outros adquiriram por seus próprios meios e de maneira artesanal em seus ambientes de origem) e lutavam contra a velha geração de sociólogos - daí em diante tratados de forma pejorativa como ensaístas ou amadores da sociologia - , munidos do conhecimento das novas metodologias e técnicas da investigação social.

Certamente, a emergência daquelas lutas deve ser compreendida em função deum novo contexto internacional, caracterizado por uma profunda transformação intelectual na cultura das ciências sociais, assim como pelo surgimento de uma série de organizações e instituições consagradas à promoção eao estabelecimento das ciências sociais no sistema cultural em geral e no sistema de educação superior, em particular.

A partir do segundo pós-guerra, as ciências sociais experimentaram uma série de mudanças significativas como parte de uma transformação mais ampla na cultura intelectual. Em termos muito gerais, tais mudanças caracterizaram-se por "um declínio da reflexão especulativa e filosófica e um otimismo generalizado acerca dos resultados que seria de se esperar, dado que se logrou um firmefundamento científico eempírico" (Bernstein, 1982, p. 27). A convicção dequeas ciências sociais diferem apenas em grau, mas não em gênero, das ciências naturais começou a difundir-se entre os cientistas sociais e cresceu a expectativa por grandes avanços, uma vez que as técnicas quesehaviam mostrado eficazes para o entendimento científico da natureza foram imitadas, modificadas e adaptadas ao universo das disciplinas que se 
ocupam da sociedade (cf. Wallerstein, 1996). 0 desenvolvimento dos métodos etécnicas de pesquisa, especialmente das técnicas quantitativas, ampliaram aquelas expectativase colocaram pela primeira vez as ciências sociais no centro da atenção e da esperança públicas (cf. Bell, 1984). A pesquisa adotou um caráter marcadamenteinterdisciplinar. Asvinculações da sociologia com a história, a antropologiaea psicologiatornaram-se maisfluidas do que no passado e o centro ou instituto de investigação foi adotado como matriz institucional para o desenvolvimento da investigação social.

Tais mudanças afetaram de modo significativo a tradição da sociologia. Astradições clássicas da sociologia formaram-se em torno dos anos de 1920 nos países europeus que naquele momento ocupavam o centro da vida intelectual: Alemanha, França e Inglaterra. No segundo pós-guerra, no entanto, e por diversas razões, a sociologia norte-americana tornou-se central ea sociologiaeuropéia, periférica. Em princípio, tal mudança seria favorecida pela precoce e sólida institucional ização al cançada pela sociologia nos Estados U nidos durante as primeiras décadas do século XX, em oposição ao que ocorreu nos países europeus, nos quais ela continuou ocupando um lugar marginal no sistema acadêmico das universidades. Seu epicentro foi a U niversidade de $\mathrm{C}$ hicago, mas rapidamente se estendeu a grande parte do sistema universitário, em especial Columbia, $\mathrm{H}$ arvard e Berkeley, que se converteram nos novos centros das ciências sociais eno lugar de assimilação de seu métier (cf. Shils, 1970).

Trajetórias e lideranças intelectuais

Q uem tomou parte dessa nova elite intelectual? Em torno de quais lideranças se constituiu a nova ciência social? Se bem que al gumas tenham sido mais expressivas do que outras, o processo que conduziu à implantação das modernas ciências sociais articulou-se em torno de certas figuras intelectuais que exibiram, al gumas mais do que outras, uma enorme capacidade deliderançaintelectual eorganizacional, essencial para esseempreendimento acadêmico.

Curiosamente, al guns líderes foram estrangeiros, ainda que dois deles, Gino G ermani e José M edina Echavarría, residissem havia certo tempo na Argentina e no M éxico, respectivamente. 0 primeiro, de origem italiana, chegara à Argentina em 1934; o segundo, nascido na Espanha, aportara no M éxico em 1939. $O$ utros dois, mais jovens, Peter H eintz e Johan G altung, eram respectivamente suíço e norueguês. N esse sentido, essa parte da histó- 
ria das ciências sociaisna América Latina pode ser lida também como outro capítulo do importante papel jogado pela "imigração intelectual" européia na implantação das ciências sociais no século XX.

Foi parte dessa geração de sociólogos que, nas décadas de 1950 e 1960, produziu uma profunda renovação das ciências sociais na América Latina, combinando a tradição mais empírica, norte-americana, com a da "grande teoria", do velho continente. José M edina Echavarría e Gino G ermani foram, talvez, seus representantes mais destacados. A trajetória da mai oria deles está associada à criação, em al guns casos, ou ao impulso, em outros, das principais instituições das ciências sociais da América Latina. Alguns foram verdadeiros construtores de instituições. A custa de talento e perseverança em um meio muitas vezes pouco hospitaleiro aos seus empreendimentos, edificaram al gumas das instituições culturais decisivas para a implantação e a legitimação das ciências sociais na América Latina: editoras e publicações especializadas, escolas desociologia e centros regionais de ensino e pesquisa.

D ois deles foram editores e tradutores exemplares. Em 1939, com a derrota dos republicanos na G uerra Civil Espanhola, M edina Echavarría emigrou para o M éxico e assumiu a direção da coleção "Sección de 0 bras de Sociología", do Fondo de Cultura Económica, uma editora fundada por Cosío Villegas em 1934. Em muito pouco tempo, o Fondo se consolidaria como uma das editoras de maior prestígio em ciências sociais na América Latina, com sucursais na Argentina, no U ruguai, no Chile, no Peru, na Colômbia, no Brasil e na Venezuela (cf. Díaz Arciniega, 1996). A té a primeira metade dos anos de 1940, teria coleções de “Economia” (1935), "Política e Direito" (1937), "Filosofia" (1942) e "Antropologia” (1944). Por intermédio de sua coleção, M edina Echavarría disponibilizou aos leitores latino-americanos inúmeros textos sociológicos. Editou Weber, $\mathrm{M}$ annheim, Tönnies, Veblen, Pareto, M ac-Iver, Lundberg, Znaniecki e Linton, entre outros. $\mathrm{N}$ a segunda metade dos anos de 1950, quando Gino Germani viabilizava a primeira carreira de sociologia na Argentina, José Luis D el maz, um dos primeiros aspirantes, comunicou-Ihe sua intenção de estudar sociologia e, diante da pergunta de $\mathrm{G}$ ermani a respeito do que sabia ou havia lido, D e Imaz respondeu: "D isse que havia lido todo o Fondo de Cultura Económica. $\mathrm{O}$ u seja, a coleção de ciências sociais que o Fondo havia publicado. Era uma maneira de simplificar, mas também uma definição" (D e Imaz, 1977, p. 125).

N essa época, Germani fez o mesmo na Argentina. D esenvolveu um imenso trabal ho de difusão intelectual como diretor das coleções "Ciencia 
y Sociedad", na editora Abril, e "Biblioteca de Psicología Social y Sociología", na editora Pai dós. Traduziu e escreveu prólogos e estudos preliminares a obras estrangeiras e se converteu no importador de uma literatura relativamente desconhecida nos meios intelectuais locais. Com ela, dotou a disciplina em particular e as ciências sociais em geral de um novo "quadro de referências". Fromm, M ead, H orney, M alinovski, Popper, Parsons e M ills foram alguns dos que integraram esse novo quadro. Seu esforço editorial operou como um poderoso agente cultural de difusão elegitimação de novas idéias, de novos vocabulários e de novos esquemas conceituais. Ampliou as fronteiras da disciplina em comparação com o modo como ela havia sido concebida até então, ampliando seu escopo por meio de diferentes tradições, intelectuais e disciplinares (cf. Blanco, 2006).

N os anos de 1940, alguns deles - especialmente José M edina Echavarría, Gino Germani e Luiz de Aguiar Costa Pinto - foram decididamente mannheimianos em sua concepção de ciência social, pensada como "saber de orientação". D urante um bom tempo, K arl M annheim foi uma referência central e uma das mais importantes fontes formadoras das concepções do mundo moderno encampadas por todos eles. M edina Echavarría foi seu tradutor e principal divulgador. Em 1943, reuniu um conjunto de ensaios com um título obviamentemannheimiano, Responsabilidad dela inteligencia: estudios sobre nuestro tiempo. Com esse viés, que supunha uma ciência social consagrada às tarefas da "planificação social" - fórmula que pouco depois seria destacada na expressão "desenvolvimento econômico" - , essa geração de sociólogos latino-americanos encontrou um modo de atribuir um papel histórico à sociologia como técnica social em condições de intervir e submeter ao controle racional os processos de mudança social, como um modo de disputar a autoridade intelectual com a elite em nome de uma nova competência intelectual. A centralidade de $M$ annheim nessa geração foi, sem dúvida, um elemento importante no nascimento de uma tradição da ciência social que asseguraria aos cientistas sociais o lugar da intelligentsia do mundo moderno.

Todoselesavaliavam demaneira positivaa sociologianorte-americana-e estavam relativamentefamiliarizados com ela- e, desde muito cedo, haviam enfatizado sua importância. Na segunda metade dos anos de 1930, JoséM edina Echavarría havia planejado estudar sociologia nos Estados U nidos ena Inglaterra, mas o início da Guerra C ivil frustrou seus planos. Em um ensaio redigido nesses anos, dizia: "[...] éevidentequeo centro da produção sociológica em língua inglesa corresponde, neste momento do século, aos Estados 
U nidos, ondea sociologia al cança um desenvolvimento extraordinário etem uma significação positiva na cultura e na educação" (M edina Echavarría, 1940). Em Sociología, teoría y técnica avaliou a sociologia norteamericana, apesar de certas limitações, como um exemplo bem-sucedido de atual ização da disciplina na direção de uma moderna ciência empírico-analítica. 0 sprimeiros escritos de $G$ ino $G$ ermani na metade dos anos de 1940 revelam que tinhaum conhecimento profundo, não usual entreossociólogosdeentão, da sociologia norte-americana (cf. Blanco, 2006). Em Teoría einvestigación en la sociología empírica, dedicou um capítulo extenso à sociologia norte-americana; em 1957, esteve por três meses em visita a universidades e centros de pesquisa do exterior, em suamaioria norte-americanos, examinando alternativas de organização da disciplina. Entabulou relações com Talcott Parsons, Robert M erton, Paul Lazarsfeld, e com uma série de pesqui sadores e professores que, pouco depois, seriam convidadosa lecionar no brilhante departamento de sociologia por elefundado. D escontentecom o ensino de sociologia no $C$ hile naquele momento, limitado à exposição e ao comentário dos grandes sociólogos dos séculos XIX eXX, Eduardo H amuy decidiu emigrar para os Estados U nidos, mais precisamente para a U niversidade de Columbia, então um dos centros acadêmicos mais expressivos no desenvolvimento dos métodos etécnicas modernos da investigação social. N os anos de 1940, Luiz de Aguiar C osta Pinto conheceu D onald Pierson, massuas intenções de doutorar-se na Universidade de C hicago foram frustradas pela embaixada dos Estados U nidos, que se recusou a Ihe conceder o visto de entrada no país (cf. Chor M aio eV illasBôas, 1999). Como professor da Flacso, Peter H eintz, que se havia formado em sociologia na Alemanha sob a orientação de René König, um dos sociólogos alemães do pós-guerra mais abertamente partidários deuma sociologia enten dida como "ciência empírica" ebastante receptivo à influência da sociologia norte-americana, foi praticamente o primeiro a difundir a concepção mertoniana da sociologia, entendida como uma disciplina composta de teorias de médio alcance (theories of the middle range). Antes de seu ingresso na Flacso, Johan G altung, discípulo dePaul Lazarsfeld, havia ensinado metodologia de pesquisa na U niversidade de Columbia.

Todos el es compartilhavam um horizontecomum de preocupaçõesinte lectuais, relativo àsnecessidades de uma modernização radical da sociedade; unia-0s, igualmente, uma visão comum da ciência social como ciência empírica (não obstante as diferenças de grau entre suas perspectivas) e um comum rechaço a todas asformas do ensaísmo edafilosofia social: 0 abandono deuma forma cultivada de exposição em nomeda precisão dasidéiasfoi um 
artigo de fé doutrinário que agitaram contra a geração predecessora. EscoIheram o radicalismo científico como forma de proteção e auto-afirmação intelectual, e legitimaram a reivindicação ao monopólio próprio e autônomo do conhecimento em nome da ciência e da "solução racional" aos problemas sociais. Procuraram deliberadamente distinguir-se dos grupos intelectuais tradicionais, defendendo um novo padrão de trabalho intelectual, regido por normas, procedimentos, valores e critérios acadêmicos e científicos de validação (cf. M iceli, 1989). Em pouco tempo, articularam-se para criar seus próprioscentros detreinamento eaprendizagem intelectual eprofissional, e também circuitos e instituições de intercâmbio intelectual. Todos el escultivaram (ou aspiraram a cultivar) o trabal ho intelectual como um fim em si mesmo, isto é, como uma atividade profissional permanente de docência e pesquisa. A universidade constituiu o centro de suas real izações pessoais, o espaço de sociabilidade intelectual, a instância decisiva de reconhecimento do mérito científico eintelectual, o horizonteúltimo, por fim, de suas expectativas, e o centro de sua vida pessoal (afetiva e profissional). Pela possibilidade dessa vida acadêmica, esses novos produtores culturais fundaram sua posição e sua imagem como uma nova elite intelectual.

As primeiras operações

Em meados dos anos de 1950, Eduardo Hamuy, no Chile, e Gino Germani, na Argentina, encontraram um terreno favorável para a renovação do ensino da disciplina. Cada um a sua maneira logrou estabelecer os primei ros dispositivos institucionais de difusão e implantação da "sociologia científica" no Cone Sul. Pouco depois, e com a colaboração de organismos internacionais distintos, essas iniciativas locais adquiriram dimensão continental a partir dos primeiros centros regionais de ensino e pesquisa.

Sem dúvida, o ingresso da "sociologia científica" no Chile associa-se aos esforços e iniciativas de Eduardo $\mathrm{H}$ amuy. Ele estudara direito e filosofia na U niversidade do Chile e, no final dos anos de 1940, dirigiu-se à U niversidade de Columbia para completar sua formação em sociologia. Apesar de não ter concluído o doutorado, freqüentou cursos que tratavam exclusivamente de métodos de pesquisa. "N ão estava interessado nos problemas teóricos porque poderia estudá-los sozinho" - recordaria mais tarde - "[...] queria aprender os métodos de investigação social que não podiam ser assimilados nos livros [...] queria saber como conduzir uma pesquisa social" (Fuenzalida, 1983). Ao mesmo tempo, foi designado professor-visitante no 
City College de N ova York, onde real izou tarefas de docência e de investigação, dirigindo uma pesquisa sobre as condições de vida dos porto-riquenhos em N ova York (o que implicou uma estadia em Porto Rico). Finalmente, entre 1950 e 1951, passou uma temporada na U niversidade de W isconsin como assistente de pesquisa. Q uando regressou ao Chile, seu projeto de implantação de uma "sociologia científica" encontrou um contexto favorável na Faculdade de Filosofia e Educação da U niversidade do Chile, e em especial da parte de seu decano, Juan Gómez M illas, que o colocou à frente do Instituto de Sociologia em 1952 (cf. Brunner, 1985).

A nomeação de $\mathrm{H}$ amuy foi duramente criticada por aqueles que até então haviam controlado o ensino de sociologia no Chile. Seus oponentes 0 acusavam de ser apenas um "estatístico", de praticar a "agrimensura social", deencher o instituto declassificadores(sorters) IBM e, por fim, de pretender introduzir no C hileum tipo de sociologia que, como a norte-americana, era vista como técnica, e não como ciência. Em todo caso, em muito pouco tempo $\mathrm{H}$ amuy transformou um velho instituto - queatéentão só existia no papel - numa moderna instituição de pesquisa. Garantiu sua estrutura, equipamentos euma biblioteca, que, na opinião dosobservadores, chegou a ser considerada a melhor da América Latina (cf. Rodríguez Bustamante, 1957). No final da década de 1950, o instituto assinava 140 revistas especializadas dos Estados U nidos, Europa, Japão, Í ndia e de agências das N ações Unidas.

Em torno de $\mathrm{H}$ amuy, reuniu-se o primeiro núcleo de sociólogos científicos. D o grupo inicial, H ernán G odoy e Raúl Samuel, seus mais próximos colaboradores nesse projeto, foram à França para estudar sociologia epsicologia social, respectivamente. $\mathrm{M}$ ais tarde, $\mathrm{H}$ amuy patrocinou a saída de O rlando Sepúlveda e D anilo Salcedo para os Estados U nidos, seguidos por G uillermo Briones. Finalmente, Luis Ratinoff foi para a Inglaterra. A esse grupo inicial se juntaram outros, como foi o caso de Enzo Faletto, que realizaria sua pós-graduação na Flacso. N a metade da década de 1950, 0 instituto começou a publicar suas primeiras pesquisas e, nesse momento, $\mathrm{H}$ amuy já havia conseguido estabelecer uma rede de contatos e relações acadêmicas com universidades, centros de pesquisa e associações profissionais de nível internacional, em especial com o C entre d'Études Sociologiques de Paris. Fruto da ligação com este último foi a investigação conjunta iniciada em 1956 sobre a consciência dos trabal hadores de duas companhias chilenas em Lota e H uachipato, da qual participaram Alain Touraine, Jean-D aniel Reynaud, Lucien BramseTorcuato D i Tella (cf. D i Tella, 1967). 
Em 1940, depois de concluir seus estudos de filosofia na Faculdade de Filosofia e Letras da Universidade de Buenos Aires, Gino Germani começou a colaborar no Instituto de Sociologia recentemente criado pelo historiador Ricardo Levene. Teve a seu cargo a seção de pesquisas de tal instituição, onde empreendeu uma pesquisa empírica pioneira sobre a classe média em Buenos Aires. N a segunda metade dos anos de 1940, entretanto, a violenta intervenção na universidade por parte das autoridades políticas que haviam recém-assumido o poder mudou o clima até aquele momento relativamente favorável, e as atividades do instituto praticamente cessaram.

A partir de então, eatémeados dos anos de 1950, G ermani desenvolveu intensa atividade intelectual em espaços não oficiais, como editor, tradutor e professor de sociologia e psicologia social no Colegio Libre de Estudios Superiores, uma instituição central da frente cultural de oposição ao peronismo. 0 desenvolvimento dessas atividades permitiu-Ihe estabelecer uma importante rede de relações e obter legitimidade e reputação no campo cultural. Estreitou laços com instituições e figuras intelectuais como José Luis Romero e Risieri Frondizi, que seriam chaves no processo de reforma universitária pós-peronista eque, de algum modo, patrocinaram a incorporação da disciplina ao sistema universitário.

A modernização universitária iniciada após a queda do peronismo criou as condições favoráveis para a prédica de Germani a favor da "sociologia científica". Suas "credenciais" antifascistas o posicionaram demanei ra favorável em relação à intelligentsia antiperonista. Em 1955, el eassumiu a direção do Instituto de Sociologia e, anos maistarde, fundou o primeiro departamento e a carreira de sociologia na Faculdade de Filosofia e Letras da U niversidadedeBuenos Aires. A disciplina, ensinada atéentão como maté ria auxiliar de outras carreiras, tornava-se autônoma.

0 desenvolvimento do programa enfrentava, entretanto, uma grave dificuldade: a falta de professores competentes, especialmente para o ensino das técnicas de pesquisa social. Para enfrentar esse problema, G ermani utilizou duas estratégias. Empreendeu um programa intensivo de cooperação com professores e pesquisadores norte-americanos e europeus. Assim, no transcurso de poucos anos, desfilaram pela instituição uma vintena de professores do exterior - Alain Touraine, Aaron Cicourel, Kalman Silvert, Irving $\mathrm{H}$ orowitz, Peter H eintz, Bernard Rosemberg, entre outros - , convertendo o departamento em uma instituição semelhante a um centro internacional de estudo e pesquisa. A especialização no estrangeiro foi o segundo cami- 
nho adotado para a formação do corpo docentee de pesquisa. A viagem aos Estados U nidos constituía uma etapa importante na assimilação do métier que Germani considerava compatível com a nova cultura intelectual. Em poucos anos, quase todos os membros do novo departamento dirigiram-se ao exterior para se aperfeiçoar. A mai oria foi para osEstados U nidos, outros foram para a Inglaterra e, alguns, para a França.

Em pouco tempo, Germani colocou em dia a disciplina, em termos intelectuaise institucionais. G arantiu a ela um repertório bibliográfico inovador e incorporou ao seu ensino a aprendizagem de técnicas de investigação social. Converteu o tradicional Instituto deSociologia em um moderno centro de pesquisa, ensino, aprendizagem e experimentação das diferentes teorias, métodos e técnicas de investigação sociológica. Adaptou a disciplina ao padrão internacional de desenvolvimento que já havia começado a manifestar-se em todo o mundo nos primeiros anos do pós-guerra. Além disso, ampliou a pesquisa sociológica em função de uma nova série de objetos: a estratificação social, a imigração, a mobilidade social, o preconceito, 0 autoritarismo, a secularização, a urbanização, o desenvolvimento econômico e a modernização.

\section{Um novo cenário internacional}

Todas essas iniciativas foram favorecidas por um novo cenário internacional. Com efeito, a transformação experimentada pelas ciências sociais coincidiu com a campanha ativa e uma forte pressão de uma série de organismos internacionais - a D ivisão de Ciências Sociais da U nião Panamericana, o D epartamento de Ciências Sociais da U nesco, o International Social Science Council e agências filantrópicas como Ford e Rockefeller determinados a difundir o modelo de um sistema intelectual moderno, voltado sobretudo ao desenvolvimento das ciências e da pesquisa empírica, especialmente das ciências sociais. Tratava-se de um programa de modernização do ensino e da pesquisa nas ciências sociais que deveria incluir, fundamentalmente, reformas nos planos de estudo e nos métodos de ensino, projetos deatualização bibliográfica ede unificação do vocabulário, criação de organizações profissionais das distintas disci plinas, e de centros einstitutos de pesquisa. A campanha apoiou-se na reivindicação da necessidade de formar especialistas em ciências sociais que fossem capazes de levar a cabo investigações empíricas nas diferentes áreas de problemas enfrentados pelos países em vias de desenvolvimento. 
A Unesco cumpriu a esse respeito um papel de grande importância. Em 1946, com o objetivo de outorgar às ciências sociais um estatuto independente das ciências naturais, foi criado o D epartamento de Ciências Sociais. Em poucos anos, o efervescente departamento, comprometido com uma perspectiva internacional sobre as ciências sociais, promoveu a criação de associações internacionais das diversas disciplinas, de centros nacionais e internacionais de pesquisa e de um sistema de publicações de caráter internacional. A coroação de todos esses esforços de criação institucional foi a fundação do International Social Science Council, por volta de 1954 (cf. Lengyel, 1966; D e Franz, 1969).

N o caso específico da América Latina, as primeiras iniciativas provieram da U nião Panamericana que, em 1948, criou a D ivisão de Ciências Sociais com o intuito de promover um programa "voltado a contribuir com o desenvolvimento dessas ciências [...] principalmente na América Latina, por ser esta uma região na qual as ciências sociais têm evoluído de forma mais Ienta do que outras disciplinas" (C revenna, 1951, p. 54). A nova agência pretendeu promover a interconexão dos cientistas sociais da região, apoiar 0 desenvolvimento dos aspectos técnicos e científicos dessas disciplinas, estimular a preparação dos cientistas sociais em centros de treinamento e fomentar a aplicação das ciências sociais para a formulação de soluções para os problemas sociais da região (cf. Crevenna, 1952). D ois anos mais tarde, a agência lançou o primeiro número de Ciencias Sociales, uma publicação bimestral dirigida por Theo Crevenna que se constituiu num dos agentes de difusão mais importantes dos novos rumos e perfis adquiridos pelas ciências sociais a partir do pós-guerra, e empreendeu um estudo, pioneiro em seu gênero, sobre a classe média na América Latina. Esta última empresa, dirigida pelo mesmo C revenna, reuniu monografias de mais de trinta cientistas sociais norte-americanos e da América L atina efoi editada pela U nión Panamericana em seis volumes (cf. Crevenna, 1950).

Em 1947, foi criada a Comissão Econômica para a América Latina (Ce pal), um organismo das $\mathrm{N}$ ações U nidas com sedeem Santiago do C hile por cujo intermédio a questão do desenvolvimento se converteu, mais ou menos na metade dos anos de 1950, no grande tema das ciências sociais na América Latina. Sob a liderança intelectual eorganizacional de Raúl Prebisch, que assumiu a direção da instituição em 1950, a Cepal tornou-se o principal centro de influência teórico-doutrinária sobre a questão do desenvolvimento. 0 mesmo ocorreu com a sua concepção de ciência social. Sem tal influência, com efeito, sem esse conjunto de idéias, crenças e atitudes dife- 
renciadas, é difícil pensar o extraordinário desenvolvimento e impulso que as ciências sociais conheceram na América Latina durante o período. N esse ano (1950), foi publicado El desarrollo económico de latinoamérica y sus principales problemas, algo como o manifesto da nova instituição, que de algum modo propiciou o "descobrimento" socioeconômico da América Latina (cf. H irschman, 1980).

Logo que assumiu a direção da Cepal, Prebisch reuniu um pequeno grupo de pesquisadores jovens, a maioria economistas, mas também alguns sociólogos - Víctor U rquidi, Jorge Ahumada, Aníbal Pinto, Cristóbal Lara e C elso Furtado, entre outros - , que constituiu uma espécie de "seita sociológica", com nexos pessoais muito intensos e animados por uma empenhada "missão" (cf. H odara, 1987). Entre os sociólogos estava José M edina Echavarría, que se vinculou ao organismo em 1952, exercendo grande magnetismo nessa geração de cientistas sociais. Prebisch conhecera M edina Echavarría no M éxico em 1944, durante as jornadas organizadas pelo Centro de Estudos Sociais do Colégio do M éxico, então dirigido por Echavarría (cf. Lida e M atesanz, 1990). "Logo me cativou sua personalidade, pela profundidade de seu pensamento, pelo ar diáfano de sua expressão, pela força e vigor que tinha...", recordaria Prebisch anos mais tarde (cf. Cardoso, 1982, p. 15).

Em todo caso, foi essa ênfase, tão típica da C epal, na importância dos fatores sociais einstitucionais no processo de desenvolvimento, assim como sua perspectiva focada mais na experiência histórica do que nos modelos dos manuais de macroeconomia, que permitiram que se estabelecesse essa aliança entre economistas e sociólogos, tão característica da produção sociológica do período e marcada também pela posição de relevo dos sociólogos, preocupados com as questões sociais vinculadas ao desenvolvimento econômico. D e acordo com essa nova posição, os problemas do desenvolvimento econômico latino-americano só podiam ser pensados em relação às características do sistema político, da estrutura social, do sistema de estratificação, da composição de suas elites políticas, econômicas, sociais e intelectuais, da natureza dos sistemas educativos e das taxas de crescimento da população, entre outros fatores. D aí em diante, a exploração dos "fatores favoráveis" ou "desfavoráveis" ao desenvolvimento tornar-se-ia praticamente uma obsessão de sociólogos, economistas e antropólogos. D e qualquer modo, a implantação da problemática do desenvolvimento econômico não apenas arrancou as ciências sociais do isolamento no qual havia permanecido até então, como propiciou uma unificação de temas e programas na 
sociologia, que veio a conectar-se com uma expectativa ao mesmo tempo política eintelectual: o projeto de modernização da sociedade ede edificação de uma ciência do desenvolvimento e da mudança planificada.

D esde então, a situação das ciências sociais nos países da América Latina estaria no centro da atenção dos principais organismos internacionais. N essa direção, em 1949, uma missão do Social Sciences Research Council enviou à América do Sul o antropólogo norte-americano Ralph Beals com o objetivo de verificar o estado das ciências sociais nessa parte do continente e avaliar as possibilidades de seu desenvolvimento (cf. Beals, 1950). No ano seguinte, o D epartamento de Ciências Sociais da Unesco encarregou o sociólogo americano John Gillin de percorrer seis países da América Latina com o mesmo fim (cf. Gillin, 1953). Em 1952, por sua vez, o International Social Science Bulletin, editado pela Unesco, consagrou um número inteiro à situação das ciências sociais na América Latina (cf. ISSB, 1952), e durante esses anos o D epartamento de Ciências Sociais da U nesco, dirigido então pelo sociólogo britânico T. H . M arshall, planejou uma série de seminários sobre ensino e pesquisa em ciências sociais na América Latina.

A conferência relativa aos países do ConeSul, celebrada no Rio deJ aneiro em 1956, seria decisiva para o futuro das ciências sociais na região. N essa reunião, com efeito, ficou acordada a criação de dois centros, um deles dedicado ao ensino e o outro à pesquisa (cf. Caval canti, 1956), acordo que seria coroado no ano seguinte, quando uma conferência intergovernamental, que reuniu os representantes de dezenove países latino-americanos, aprovou a criação da Faculdade Latino-Americana de Ciências Sociais (Flacso), em Santiago do Chile, e do Centro Latino-Americano de Pesquisa em Ciências Sociais (Clapcs), no Rio de Janeiro. Este último começou a funcionar no mesmo ano de sua criação, sob a direção do sociólogo brasileiro Luiz de Aguiar Costa Pinto. No ano seguinte, foi iniciada a publicação de América Latina, o primeiro boletim regional em ciências sociais. A Flacso entrou em vigência no ano seguinte, a partir da criação da Escola Latino-Americana de Sociologia (ELAS), inicialmente sob a direção de osé M edina Echavarría e depois do especial ista da U nesco Peter $\mathrm{H}$ eintz. Assim teve início o primeiro curso regional de sociologia, uma criação institucional francamente inovadora, que transcendia os limites nacionais ou territoriais, com um programa nitidamente internacional, quer em relação aos estudos realizados e ao recrutamento dos professores, quer no que diz respeito à composição do corpo docente e à coordenação de suas atividades, inclusive o treinamento 
dos alunos. A renovação das ciências sociais ea correlativa emergência dessa nova elite de produtores culturais devem ser compreendidas, então, no cruzamento destes processos: 0 de uma institucionalização gradual porém firme das ciências sociais na região e o da adoção de um padrão internacional de desenvolvimento.

Infra-estrutura regional e formação de uma rede intelectual

A criação da Flacso e do Clapcs articulou e proporcionou um estatuto regional a uma série de iniciativas limitadas até então aos espaços nacionais. 0 comitê diretivo conjunto de ambas instituições foi formado por $\mathrm{G}$ ino Germani (Argentina), O rlando Carval ho (Brasil), Eduardo H amuy (Chile), JoséR afael Arboleda (C olômbia), 0 scar C havez Ezquivel (C osta Rica), Lucio M endieta y N úñez (M éxico), I saac G anón (U ruguai) e Salcedo Bastardo (Venezuela). Em 1959, Lucio M endieta y N úñez foi substituído no comitê da Clapcs por Pablo G onzález Casanova. G ustavo Lagos M atus e Luiz deA guiar Costa Pinto foram designados diretores da Flacso edo Clapcs, respectivamente.

A Flacso era essencialmenteum instituto depós-graduação. Suafinalidade era a formação de especialistas em ciências sociais, com o propósito de complementar a formação oferecida pelas universidades da região. Com efeito, dada a escassez defundos ea fal ta de recursos qualificados, as universidades nacionais não estavam, naquele momento, em condições de constituir centrosnacionais depós-graduação. A criação daFlacso foi pensada preci samentepara superar esseobstáculo, efoi concebida como uma instituição interdisciplinar (sociologia, economia, administração pública, ciência política etc.), ainda que durante o período aqui considerado, e por razões de ordem financeira, suas atividades tenham ficado limitadas ao ensino de sociologia no âmbito desua Escola L atino-Americana de Sociologia (ELAS) já em 1965 seria criada a Escola Latino-Americana de Ciência Política eAdministração. A ELAS, cujos objetivoscentraisgiraram em torno da “implantação deuma metodologia notadamentecientíficano exercício da disciplina naAmérica Latina" edeuma "visão integral do desenvolvimento econômico e social", oferecia um curso de dois anos em sociologia para latino-americanos, articulado em torno de três pilares: teoria sociológica; metodologia ge ral etécnicas de pesquisa; aspectos sociológicos do desenvolvimento econômico esocial. D ois princípios articulavam em termos pedagógicos o ensino: integração da metodologia e da teoria com a pesquisa. 
A ELAS, que rapidamente converteu-se em um poderoso centro internacional e destino quase obrigatório de muitos aspirantes a uma formação pós-graduada em ciências sociais, cumpriu a esse respeito um papel notável naformação das primeiras gerações desociólogos modernosou científicose, por conseguinte, na formação dessa nova elite intelectual. Proporcionou a seus aspirantes treinamento em pesquisa empírica eformação teórica, o que tornou possível a realização de investigações sofisticadas. Com uma vintena de formados por ano, essa Escola contou com uma equipe reduzida de docentes: três professores em tempo integral, da categoria "pessoal docente superior", edois em tempo parcial, da categoria "pessoal docentemédio". 0 ingresso de alunos novos ocorria a cada dois anos, em função do número reduzido de professores. Durante os primeiros anos, e com o objetivo de desenvolver programas de cooperação científica, estabeleceu-seuma sériede convênios com distintos centros universitários europeus e norte-americanos, em especial com a É cole Pratique des $\mathrm{H}$ autes Études, com a U niversidade da C arolina do $\mathrm{N}$ orte e com o $\mathrm{N}$ ational $\mathrm{O}$ pinion Research C enter, da U niversidade de Chicago.

$\mathrm{O}$ mentor do programa da ELAS foi Peter $\mathrm{H}$ eintz, quese havia formado em economia política na U niversidade de Z uriquee, mais tarde, em sociologia na U niversidade de Colônia. Em 1957, já na condição de especialista da U nesco, elaborou um informe fortemente negativo sobre o ensino da disciplina nos principais países da América Latina (cf. H eintz, 1957). Segundo ele, o caráter predominantemente humanista desse ensino - que dificultava uma formação científica - , a crescente desvinculação entre 0 ensino universitário e a investigação científica, e a falta de preparação dos professores nos modernos métodos e técnicas de pesquisa aconsel havam uma urgente e "fundamental reorientação" do ensino da disciplina, que devia ser empreendida, segundo H eintz, pelas agências cujas atividades estavam diretamente dirigidas à "difusão de uma sociologia moderna nessa área do mundo" (H eintz, 1957, p. 75).

Em 1958, H eintz incorporou-se à Escola e, entre 1960 e 1965, assumiu sua direção. Filiado à concepção mertoniana da sociologia como ciência teórica e empírica, que seria refletida em seu Curso de sociologia (1960), a idéia geral do programa consistia em oferecer model os de investigação com o fim de prover projetos de pesquisa relativamente simples para serem usados por todos os professores de sociologia da América Latina, como meios para um treinamento intensivo dos estudantes na "pesquisa empírica teoricamente orientada", e testar em contextos socioculturais diferentes uma 
série de hipóteses tomadas da literatura contemporânea sobre teoria sociológica (cf. H eintz, 1963). O s modelos de investigação de H eintz faziam referência a dez tópicos: orientações valorativas, expectativas crescentes das massas, socialização familiar, industrialização, urbanização, organização rural, potencialidades políticas das classes médias e baixas, organização racional, inovação tecnológica e novas elites.

0 programa, segundo H eintz, devia combater a desconfiança em relação à teoria que havia sido gerada com a introdução da sociologia moderna na América Latina como rechaço ao predomínio da especulação ou da "fil osofia social". A conseqüência imediata desse rechaço era a preferência por surveys ou por inventários meramente descritivos que, por não estarem precedidos nem seguidos de considerações teóricas explícitas, careciam de valor explicativo ou depredição. Contraisso, $\mathrm{H}$ eintz sublinhava que "a sociologia moderna é uma ciência empírica e teórica”. Em tal sentido, os modelos de investigação estavam destinadosa combater essatendência refratária àteoria na sociologia restabelecer um novo equilíbrio entreteoria epesquisa empírica (cf. Idem, 1963).

O utra figura influentena ELAS foi o sociólogo e matemático norueguês Johan $\mathrm{G}$ altung. Discípulo de Paul Lazarsfeld, sua principal especialidade era a metodologia da investigação social. "Foi nosso mentor" - disse Edelberto Torres Rivas, um de seus alunos na ELAS - "e, sem dúvida, o que mais influenciou naquele momento a formação de várias gerações de latino-americanos" (apud Bataillon, 2006). Em 1966, a seção de sociologia da editora Eudeba, assessorada por Germani, publicou em dois volumes suas aulas na Flacso, Teoría y métodos en la investigación social.

A experiência dos dois centros foi relativamente bem-sucedida. D urante a primeira década, a Flacso ofereceu cursos avançados em sociologia a 163 jovens licenciados, em sua grande mai oria provenientes dos países do C one Sul (43 do Chile, 32 da Argentina, 25 do Brasil e entre oito e doze do M éxico, Peru, Colômbia e U ruguai). N esse mesmo período, o Clapcs chegou a empreender 37 projetos de pesquisa vinculados a problemáticas distintas da América Latina, algumas delas iniciadas pelo próprio Clapcs e outras a pedido de outras instituições ou em colaboração com elas.

A Escola de Sociologia da Flacso não se limitou a articular esforços e iniciativas preexistentes, mas estimulou e promoveu em boa medida o cultivo das ciências sociais onde a infra-estrutura institucional era muito incipiente. Assim, por exemplo, a expansão e a institucional ização que a sociologia experimentou no U ruguai durante esses anos se beneficiaram 
enormemente do espaço institucional gerado em torno da Flacso edo Clapcs. Em princípio, I saac $\mathrm{G}$ anón, um dos principais animadores da sociologia no U ruguai, integrou o comitê diretivo de ambas instituições, e como parte dessa gestão M ontevidéu foi incluída como uma das capitais investigadas na pesquisa sobre estratificação e mobilidade social. Além disso, a primeira geração de sociólogos uruguai os formou-se na Flacso (cf. D eSierra, 2005).

N uma perspectiva histórica, portanto, esses centros emergentes, tanto de planificação e desenvolvimento, como de ensino e pesquisa, cumpriram um papel estratégico no desenvolvimento ena expansão dasciências sociais na região. $\mathrm{N}$ ão apenas contribuíram para a legitimação das ciências sociais nos diferentes países do Cone Sul, como também constituíram os espaços de formação de uma nova cultura intelectual em ciências sociais e de funcionamento das redes intelectuais e institucionais que operaram como um importante dispositivo institucional de promoção e difusão da sociologia científica ou moderna, e de articulação dessa nova elite de produtores culturais. Além disso, e quando a sociologia ainda possuía um caráter marcadamente regional antes da renovação, os centros também contribuíram para garantir esse caráter regional e ao mesmo tempo promoveram uma nova agenda de debates sobre a situação da América L atina: a estratificação e a mobilidade sociais, o autoritarismo, o desenvolvimento econômico ea modernização.

Em pouco tempo foi tecida uma poderosa rede de intercâmbio intelectual e de atividades conjuntas entre todas essas instituições e al guns de seus membros. $\mathrm{H}$ amuy teve uma participação importante na organização dos aspectos referentes ao ensino nos primeiros anos da Flacso. Ademais, a própria sede daFlacso no C hilefoi implantada propositadamentenas cercanias do Instituto de Sociologia dirigido por $\mathrm{H}$ amuy. Ao que parece, foi também $\mathrm{H}$ amuy quem convenceu José M edina Echavarría a assumir a direção da Escola Latino-Americana de Sociologia da Flacso. Em 1958, o Clapcs incluiu em seu programa de investigações uma pesquisa sobre estratificação e mobilidade social em quatro capitais da América Latina (Rio de Janeiro, BuenosAires, Santiago eM ontevidéu), da qual participaram Gino Germani, Eduardo H amuy, T. Pompeu Accioly, Isaac Ganón e um observador da Cepal, Gustavo D urán. M ais ainda, o documento de trabalho inicial, redigido em 1957 por Gino Germani, foi discutido esse ano em uma reunião celebrada no Instituto deSociologia da U niversidade do C hile, dirigido por $\mathrm{H}$ amuy, aproveitando a participação de muitos dos que estiveram presentes no IV Congresso Latino-Americano de Sociologia, realizado no C hile. 
0 intercâmbio alcançou também atividades de ensino, formação de recursos e publicações. M uitos deles - Peter H eintz, Lucien Brams, José M edina Echavarría, Luiz de Aguiar Costa Pinto, Gino Germani, Alain Touraine, George Friedmann - participaram indistintamente em atividades de ensino e de pesquisa na Flacso, no D epartamento de Sociologia de Buenos Aires, no Clapcs e no Instituto de Sociologia da U niversidade do C hile. Em BuenosAires, Gino G ermani promoveu na editoradaU niversidadede BuenosAires, Eudeba, a edição dedois cursos daFlacso, o Curso desociología, de Peter $\mathrm{H}$ eintz, editado originariamente por Andrés Bello no Chile, e o de Johan Galtung, Teoría y métodos en la investigación social (1966). Em sua própria coleção, G ermani incluiu dois títulos de Luiz de Aguiar C osta Pinto, La sociología del cambio y el cambio de la sociología (1963), dedicado a Eduardo H amuy e a Gino G ermani, e Estructura de clases y cambio social (1964).

A realização, ao longo dessesanos, de uma série deencontrosinternacionais, organizados e auspiciados pel os distintos organismos regionais einternacionais ( $\mathrm{ONU}$, C epal, Flacso, Clapcs), não somente ampliou esse circuito de intercâmbio intelectual, como também operou como uma rede de organização e de programação da agen da temática que daí em diante dominaria o debate nas ciências sociais: a estratificação e a mobilidade social, a urbanização, o desenvolvimento econômico, a mudança social e política, entre outros.

Em 1961, durantea C onferência Interamericana sobre Pesquisa eEnsino de Sociologia, realizada em Palo Alto, Califórnia, a "sociedade intelectual" desses novos produtores culturais alcançou um momento expressivo com a criação do Grupo Latino-Americano para o D esenvolvimento da Sociologia. A reunião foi promovida pelo Social Science Research Council, o que mostra o importante grau de articulação internacional alcançado. Os argumentos formulados na declaração de propósitos, que foi firmada por G uillermo Briones, Luiz deAguiar Costa Pinto, Peter H eintz, Gino G ermani e 0 rlando Fals Borda, eram os mesmos que se vinham repetindo nos diversos foros internacionais. Com efeito, se justificava a necessidade de adaptar a disciplina aos padrões internacionais de desenvolvimento e de promover a elevação do nível acadêmico e científico por meio de uma formação especializada eda dedicação exclusiva a docência e pesquisa. A poiada pela C epal e pela Flacso, a declaração contou, ademais, com a adesão de Florestan Fernandes, Eduardo H amuy, José Silva M ichelena, Lucien Brams e Pablo G onzález $C$ asanova. Ainda que não se tratasse de uma associação de caráter 
formal, o novo agrupamento funcionou como um meio de comunicação alternativo aos já existentes, como a Associação Latino-Americana de Sociologia e as sociedades nacionais de sociologia, a mai oria delas controladas pelos representantes da "sociologia de cátedra", e havia de constituir um componente a mais desse circuito institucional emergente, igualmente alternativo, constituído por organismos regionais como C epal, Flacso, C lapcs e Unesco.

Referências Bibliográficas

Bataillon, Gilles. (2006), "Entrevista com Edelberto Torres Rivas". I stor, VI (24): 102-121.

Beals, Ralph. (1950), "The social sciences in South America”. Social Sciences Re search Council Items, 4 (1).

BeLL, D aniel. (1984), Las ciencias sociales desde la Segunda Guerra M undial. M adri, Alianza.

Bernstein, Richard. (1982), La reestructuración de la teoría social y política. M éxico, F.C.E.

Blanco, Alejandro. (2004), "M ax Weber na Argentina (1930-1950)". D ados. Revis ta de Ciências Sociais, 4, Instituto Universitário de Pesquisas do Rio de Janeiro, Iuperj.

. (2006), Razón y modernidad: Gino Germani y la sociología en la Argentina. Buenos Aires, Siglo XXI.

Brun ner, J osé Joaquín. (1985), "Los orígenes de la sociología profesional en Chile". D ocumento de Trabajo n. 260, Programa Flacso, Santiago de Chile.

C ARD o so, Fernando H . et al. (1982), M edina Echavarría y la sociología latinoamericana. M adri, Ediciones Cultura H ispánica/Instituto de Cooperación I beroamericana. CavalcantI, Themistocles B. (1956), "Round Table on the U niversity Teaching of the Social Sciences in South América". International Social Science Bulletin, VIII (2).

Chor Malo, M arcos \& Villas BôAs, Glaucia (orgs.). (1999), I deais de modernidade e sociologia no Brasil : ensaios sobre Luiz de Aguiar Costa Pinto. Porto Alegre, Editora da UFRGS.

Crevenna, Theo (ed.). (1950), M ateriales para el estudio de la clase media en la América Latina. Washington, Unión Panamericana, 6 vols. . (1951), "Plan de trabajo y actividades en materia de las ciencias sociales". Ciencias Sociales, Unión Panamericana, 2 (10). . (1952), "The social sciences in the O rganization of American States". International Social Science Bulletin, IV (3). 
D e Franz, M arie-Anne. (1969), “Implanting the social sciences: a review of U nesco's endeavours". International Social Science Journal, XVIII (4), Unesco.

D E Im AZ, José Luis. (1977), Promediando los cuarenta. Buenos Aires, Sudamericana. D E SierRA, Jerónimo. (2005), "Social sciences in U ruguay". Social SciencesI nformation sur les Sciences Sociales, 44 (2-3).

D I T ELLA, Torcuato et al. (1967), Sindicato y comunidad: dos tipos de estructura sindical latinoamericana. Buenos Aires, Editorial del Instituto.

Díaz Arciniega, Víctor. (1996), Historia de la casa: Fondo de Cultura Económica 1934-1996. M éxico, F.C.E.

FLACSO. (1962), Informe sobre el proyecto de creación de las Escuelas Latinoamericanas de Economía y Administración Pública. Santiago de Chile, Editorial Universitaria.

Fuenzalida, Edmundo. (1983), "The reception of 'scientific sociology' in Chile". Latin American Research Review, XVIII (2).

Germanı, Gino. (1946a), "Sociología y planificación". Boletín de la Biblioteca del Congreso N acional, n. 57, 58, 59. Buenos Aires. - (1946b), Teoría e investigación en la sociología empírica. Buenos Aires, inédito. . (1964), La sociología en la América Latina: problemas y perspectivas. Buenos Aires, Eudeba.

GilLIN, John. (1953), "La situación de las ciencias sociales en seis países sudamericanos". Ciencias Sociales, IV (19).

H EINTZ, Peter. (1957), "Some specific aspects of the teaching of sociology in Latin American countries". International Social Science Bulletin, IX (1). . (1963), "Research models for Latin America". International Social Science Journal, XV (4).

H IRSChm AN, Albert. (1980), "Auge y caída de la teoría económica del desarrollo". El trimestre económico, XLVII (4), n. 188, M éxico.

H odAra, Joseph. (1987), Prebish y la Cepal: sustancia, trayectoria y contexto institucional. M éxico, El Colegio de M éxico.

International Social Science Bulletin (ISSB), IV (3), 1952.

Jones, Robert C. \& JONES, Ingeborg H . (1950), "Inter-american cooperation in the social sciences". International Social Science Bulletin, II (4).

LANGRod, G. (1957), "The establishement of two regional centres for teaching and research of the social sciences in Latin America". International Social Science Bulletin, IX (3).

Lengyel, Peter. (1966), "Two decadas of social science at U nesco". International Social Science Journal, XVIII (4), Unesco.

Lida, Clara \& Matesanz, José Antonio. (1990), El Colegio de M éxico: una hazaña cultural (1940-1962). M éxico, El Colegio de M éxico. 
Medina Echavarría, José. (1940), Panorama de la sociología contemporánea. M éxico,

La C asa de España en M éxico.

- (1941), Sociología: teoría y técnica. M éxico, F.C.E.

M ICELI, Sergio (org.). (1989), H istória das ciências sociais no Brasil. São Paulo, Vértice/Editora Revista dos Tribunais.

Poviñ A, Alfredo. (1941), H istoria de la sociología en Latinoamérica. M éxico, Fondo de Cultura Económica.

Rodríguez Bustam ante, N orberto. (1957), “Informe sobre el IV Congreso Latinoamericano de Sociología". Facultad de H umanidades y Ciencias de la Educación, Universidad Nacional de La Plata.

SHILS, Edward. (1970), "Tradition, ecology and institution in the history of sociology". D aedalus, 99 (4).

VILlAs BôAs, Glaucia. (2006a), "Uma geração de 'manheimianos'. In: M udança provocada: passado e futuro no pensamento sociológico brasileiro. Rio de Janeiro, FGV.

. (2006b), "O s portadores da síntese (sobre a recepção de Karl M annheim)".

In: . A recepção da sociologia alemã no Brasil. Rio de Janeiro, Topbooks.

W allerstein, Immanuel (coord.). (1996), Abrir las ciencias sociales. M éxico, Siglo $X X I$.

\section{Resumo}

Ciências sociais no Cone Sul e a gênese de uma elite intelectual (1940-1965)

Este trabalho reconstrói o processo de constituição e ascensão de uma nova classe de produtores intelectuais, a dos cientistas sociais, detentores de uma competência intelectual e técnica exclusiva, e depositários de uma formação acadêmica inovadora. De um lado, são examinadas as distintas iniciativas e os principais dispositivos culturais e institucionais de difusão e implantação da sociologia moderna em al guns países da América Latina, assim como as trajetórias intelectuais de seus principais protagonistas; e, de outro, o contexto intelectual e político mais geral em que ocorreu esse processo, em especial o papel desempenhado por uma série de organismos regionais e internacionais na formação de uma rede intelectual.

Palavras-chave: Ciências sociais; Institucionalização; Elite intelectual; Trajetórias intelectuais; O rganismos internacionais.

\section{Abstract}

Social sciences in the Southern Cone and the birth of an intellectual elite (1940-1965)

This work reconstructs the formation and rise of a new class of intellectual producers, the social scientists, owners of an exclusive intellectual and technical expertise, 
and recipients of an innovative form of academic training. Firstly, the text examines the distinctive initiatives and the main cultural and institutional devices used in the spread and implementation of modern sociology in a number of Latin American countries, as well as the intellectual careers of its main protagonists. Secondly, it looks at the overall intellectual and political context in which this process occurs, especially the role performed by a series of regional and international institutions in forming an intellectual network.

Keywords: Social sciences; Institutionalization; Intellectual elite; Intellectual careers; International institutions.

Texto recebido em 16/ 3/2007 e aprovado em $16 / 3 / 2007$.

Alejandro Blanco éformado em Sociologia pelaFaculdadedeCiências Sociais da Universidade deBuenosAires, é mestre em Sociologia da Cultura e Análise Cultural pela Universidade Nacional de $\mathrm{Ge}$ neral San M artín edoutor em História na Fa culdade de Filosofia e Letras da Universidade de Buenos Aires. É membro do Programa de H istória Intelectual daU niversidadeN acional de Quilmes e pesquisador do Conselho $\mathrm{N}$ acional de Investigações Científicas e T écnicas (Conicet). É autor de Razón y modernidad: Gino Germani y la sociología en la Argentina (Buenos Aires, Siglo XXI, 2006). Email: ablanco@unq.e du.br. 